\title{
Accuracy of Ultrasound Determination of Estimated Fetal Weight in Small for Gestational Age Pregnancies
}

\author{
Manoj Kumar Malhotra ${ }^{1}$, Deepali Jain ${ }^{2^{\star}}$ \\ 1PG Resident (IIIrd year), 2"Professor, Department of Obstetrics and Gynaecology, \\ JLN Medical College and Associated Group of Hospital, Ajmer, Rajasthan, India.
}

\begin{abstract}
Background: Ultrasound is more accurate when it follows clinical diagnosis of intrauterine growth restriction. Based on the review of literature, we recommend routine ultrasound examination in the third trimester for timely diagnosis of SGA.

Aims \& Objectives: This study was done to assess the accuracy of ultrasound examination in estimation of fetal weight from 37 weeks to 40 weeks of pregnancy in appropriate for gestational age and small for gestational age.

Material \& Methods: The prospective randomized observational study whereby all ultrasonic fetal weight estimations were carried by prosound i4 ALOKA. Fifty pregnant women at term with appropriate for gestational age pregnancy and fifty other women at term with small for gestational age pregnancy had ultrasonic estimation of fetal weight performed within a week of delivery.

Results: The present study showed that majority of subjects of control and study group were in the age group 21 to 30 years and co-efficient of correlation $(r)=0.6981$ suggest high positive correlation between actual birth weight and estimated fetal weight by ultrasound.

Conclusion: The study showed that ultrasound predicts the fetal weight in both categories with a mean absolute error of
\end{abstract}

\section{INTRODUCTION}

Accurate determination of fetal weight prior to delivery can have a significant bearing on the management decision in labour, thereby markedly improving perinatal outcome. In last few decades, the estimation of fetal birth weight has advanced from estimation by physical examination to fetal ultrasound using multiple parameters. This has increased the accuracy of the fetal weight estimation significantly. ${ }^{1}$ Multiple formulae have been developed for the estimation for birth weight using ultrasound measurement. At present, fetal ultrasound is extensively used to estimate the fetal weight. Fetal growth has been divided into three phases. The initial phase of hyperplasia occurs in the first 16 weeks and is characterized by a rapid increase in cell number. The second phase, which extends up to 32 weeks gestation, includes both cellular hyperplasia and hypertrophy. After 32 weeks, fetal growth is by cellular hypertrophy, and it is during this phase that most fetal fat and glycogen are accumulated. The corresponding fetal growth rates during these three phases are $5 \mathrm{~g} /$ day at 15 weeks gestation, 15 to $20 \mathrm{~g} /$ day at 24 weeks, and 30 to $35 \mathrm{~g} /$ day at 34 weeks. $^{2}$

Fetal weight can be estimated clinically by Johnson's formula as height of the uterus above the symphysis pubis in centimeters minus 12 , if the vertex is at or above the level of ischial spines or minus 11 , if the vertex is below the level of ischial spines-
1.092435 USG estimation of fetal weight can be used to predict the birth weight with high degree of accuracy and plan delivery and neonatal management for a better neonatal outcome.

Keywords: Ultrasound, Fetal weight, AGA, SGA, Gestational age.

\section{${ }^{*}$ Correspondence to:}

\section{Dr. Deepali Jain}

Professor, Department of Obstetrics and Gynaecology, JLN Medical College and Associated Group of Hospital, Ajmer, Rajasthan, India.

\section{Article History:}

Received: 28-05-2016, Revised: 06-06-2016, Accepted: 17-06-2016

\begin{tabular}{|l|c|}
\hline \multicolumn{2}{|c|}{ Access this article online } \\
\hline $\begin{array}{l}\text { Website: } \\
\text { www.jimrp.com }\end{array}$ & Quick Response code \\
DOI: & \\
10.21276/ijmrp.2016.2.4.014 & \\
\hline
\end{tabular}

multiplied by 155 in either case gives the weight of the fetus in grams. This is however, applicable only in vertex presentation. However, the approximate size of the fetus is modified by the amount of liquor and thickness of the abdominal wall. ${ }^{3}$ When the pregnancy cannot be dated accurately by clinical evaluation, sonography is accepted as the most useful and accurate tool for estimating gestational age and fetal weight.

SGA refers to a fetus that has failed to achieve a specific biometric or estimated weight threshold by a specific gestational age. Various thresholds $\left(2.5^{\text {th }}, 3^{\text {rd }}, 5^{\text {th }}, 10^{\text {th }}, 15^{\text {th }}\right.$, and $25^{\text {th }}$ centiles and $1.0,1.5$ or 2.0 standard deviations below the population average) are used for various fetal measures. The commonly used threshold is the tenth centile for abdominal circumference and estimated birth weight. ${ }^{4}$ SGA fetuses are heterogeneous group comprising fetuses that have failed to achieve their growth potential (fetal growth restriction, FGR) and fetuses that are constitutionally small. Approximately $50-70 \%$ of fetuses with a birth weight below tenth centile for gestational age are constitutionally small ${ }^{5}$ and the lower the centile for defining SGA, the higher the likelihood of FGR.

SGA fetuses are at greater risk of stillbirth, ${ }^{6}$ birth hypoxia, ${ }^{6}$ neonatal complications, ${ }^{6}$ impaired neurodevelopment, ${ }^{7}$ and possibly type 2 (non-insulin-dependent) diabetes and 
hypertension in adult life. ${ }^{8}$ The reason that studies on SGA fetuses have shown poor perinatal outcome is likely to be the high incidence of true fetal growth restriction in this group.

The etiology of IUGR is very diverse and the presentation insidious and confusing hence diagnosis can be quite difficult especially in early stages. Detailed history taking, looking out for the high risk factors and vigilant clinical monitoring, along with use of Ultrasonography, and Doppler studies, are essential for early and accurate diagnosis. Once the diagnosis of IUGR is reached the mother and foetus should be under close scrutiny, any complicating factors identified should be ameliorated (whenever possible) and all attempts should be made to take the pregnancy to viability and maturity. The delivery of these high risks, delicate fetuses should be handled with extreme care as these babies cannot withstand prolonged labour. Presence of expert neonatal support is also essential for resuscitation as well as follow-up to look for long-term complications.

Before the development of ultrasonography, delayed fetal growth was indicated by low maternal weight gain, Leopold maneuvers and fundal height measurement. Currently, IUGR is still often suspected on the basis of fundal height measurement. A significant lag in fundal height is a 4-cm or greater difference than expected for gestational age. However, even carefully performed fundal height measurements only have a 26 to 76 percent sensitivity in predicting IUGR. ${ }^{9}$ IUGR is frequently detected in a pregnancy with a less-than-expected third-trimester weight gain (100 to $200 \mathrm{~g}$ per week) or as an incidental finding on ultrasound examination when fetal measurements are smaller than expected for gestational age. The main prerequisite for determining IUGR is precise dating. The most accurate dating method uses ultrasound examination at 8 to 13 weeks. Later ultrasound examinations are helpful, but the margin of error is increased. The date of the last menstrual period, early uterine sizing and detection of fetal heart tones are helpful ways to accurately date the pregnancy. Most cases of IUGR present during the third trimester, which makes them difficult to accurately diagnose. This is especially true if the patient has presented for prenatal care at a late stage. The physician must determine if the dating is incorrect and the fetal size is actually normal or if the mother truly needs further evaluation for IUGR.

Ultrasonography is normally the first study done to assess IUGR. This test loses its accuracy as the pregnancy progresses, but the sensitivity and positive predictive value can be improved if several variables are combined. ${ }^{10}$ These variables include estimated fetal weight, head circumference and abdominal circumference. The present study to evaluate the accuracy of ultrasound in determination of estimated fetal weight in small for gestational age pregnancies and compare accuracy in AGA and SGA fetus.

\section{MATERIAL \& METHODS}

The prospective randomized observational study whereby all ultrasonic fetal weight estimations were carried by prosound i4 ALOKA in the department of Obstetrics and Gynaecology, Jawahar Lal Nehru Medical College and Associated Group of Hospital, Ajmer from Dec. 2014 to Nov. 2015. Fifty pregnant women at term with appropriate for gestational age pregnancy and fifty other women at term with small for gestational age pregnancy had ultrasonic estimation of fetal weight performed within a week of delivery. Fetal weight was estimated by the Hadlocks formula: Hadlock'sformula ${ }^{11}$ :

$\log _{10} \mathrm{EFW}=1.3596-0.0038 \mathrm{AC} \times \mathrm{FL}+0.0064 \mathrm{HC}+0.00061$ $B P D \times A C+0.0424 \mathrm{AC}+0.174 \mathrm{FL}$

$E F W=$ estimated fetal weight $(\mathrm{g})$,

$\mathrm{BPD}=$ biparietal diameter $(\mathrm{cm})$

$\mathrm{FL}=$ femur length $(\mathrm{cm})$,

$\mathrm{AC}=$ abdominal circumference $(\mathrm{cm})$

In our study we defined small for gestational age neonate as one with birth weight equal to or below $10^{\text {th }}$ percentile for gestational age according to normograms proposed by Alexander et al. This comprised the test group. Appropriate for gestational age neonate has been defined as one with birth weight above $10^{\text {th }}$ percentile and below or equal to $90^{\text {th }}$ percentile for gestational age according to normograms proposed by Alexander et al. This formed the control group.

Alexander's table of percentiles of birth weight for gestational age

\begin{tabular}{|c|c|c|c|}
\hline Weeks & $10^{\text {th }} \%$ tile & Average & $90^{\text {th }} \%$ tile \\
\hline 20 & 275 & 412 & 772 \\
\hline 21 & 314 & 433 & 790 \\
\hline 22 & 376 & 496 & 826 \\
\hline 23 & 440 & 582 & 882 \\
\hline 24 & 498 & 674 & 977 \\
\hline 25 & 558 & 779 & 1138 \\
\hline 26 & 625 & 899 & 1362 \\
\hline 27 & 702 & 1035 & 1635 \\
\hline 28 & 798 & 1196 & 1977 \\
\hline 29 & 925 & 1394 & 2361 \\
\hline 30 & 1085 & 1637 & 2710 \\
\hline 31 & 1278 & 1918 & 2986 \\
\hline 32 & 1495 & 2203 & 3200 \\
\hline 33 & 1725 & 2458 & 3370 \\
\hline 34 & 1950 & 2667 & 3502 \\
\hline 35 & 2159 & 2831 & 3596 \\
\hline 36 & 2354 & 2974 & 3668 \\
\hline 37 & 2541 & 3117 & 3755 \\
\hline 38 & 2714 & 3263 & 3867 \\
\hline 39 & 2852 & 3400 & 3980 \\
\hline 40 & 2929 & 3495 & 4060 \\
\hline
\end{tabular}


Large for gestational age neonates weighing above $90^{\text {th }}$ percentile for gestational age were excluded from the study. We compared estimated fetal weight with the birth weight after adjusting EFW by adding $25 \mathrm{~g}$ for each day between the ultrasound measurement and delivery.

The observed measurements of fetal weights were those obtained by ultrasound measurements of the biometric variables within 7 days of delivery plus any additional weight gain between the ultrasound scan and delivery.

Between 37 and 40 week's gestation, the average observed weight gain was $25 \mathrm{~g}$ per day. ${ }^{12}$ Therefore; $25 \mathrm{~g}$ was added to the EFW for each day between the ultrasound scan and delivery of the fetus. The true state, generally known as the reference standard, was the documented birth weight obtained at delivery by labour room electronic weighing machine Smart Care Digital Baby Scale. Before enrolling the patient into the study, patients were explained the type and nature of the study and valid consent was taken. On admission the age, the parity, maternal age, body weight, antenatal risk factor if any of the patient was taken into consideration.

\section{RESULTS}

The present study showed that majority of subjects of control and study group were in the age group 21 to 30 years (table 1). Coefficient of correlation $(r)=0.6981$ suggest high positive correlation between actual birth weight and estimated fetal weight by ultrasound (table $2 \& 3$ ). In our study table no. 4 showed the comparison between AGA \& SGA.

\section{DISCUSSION}

Prenatal identification of SGA neonates is important because it can reduce perinatal mortality, influence the location and time of delivery, and mitigate neonatal complications. We need accuracy in predicting SGA neonates for two reasons:

(1) High likelihood of abnormal fetal growth in our population,

(2) High rate of neonatal complications and stillbirth associated with intrauterine growth restriction.

Majority of subjects of control and study group were in the age group of 21-30 years. In our study group greater number of subjects were below the poverty line with respect to control group, this fact will have a bearing on the fetal weight.

Table 1: Distribution of subjects according to the age

\begin{tabular}{cccc}
\hline S.No. & Age(yrs) & No. of Control \% & No. of cases \% \\
\hline $\mathbf{1}$ & $15-20$ & $14 \%$ & $12 \%$ \\
$\mathbf{2}$ & $21-25$ & $48 \%$ & $62 \%$ \\
$\mathbf{3}$ & $26-30$ & $38 \%$ & $26 \%$ \\
& Total & $100 \%$ & $100 \%$ \\
\hline
\end{tabular}

Table 2: Correlation between actual birth weight and estimated fetal weight by ultrasound in study group at gestational age 37 to 40 weeks

\begin{tabular}{cccccc}
\hline S.No. & Birth Weight & EFWc & S.No. & Birth Weight & EFWc \\
\hline $\mathbf{1}$ & 2450 & 2250 & 26 & 1980 & 2200 \\
$\mathbf{2}$ & 2100 & 2000 & 27 & 1800 & 1950 \\
$\mathbf{3}$ & 2200 & 2340 & 28 & 2150 & 2400 \\
$\mathbf{4}$ & 2300 & 2460 & 29 & 1750 & 1600 \\
$\mathbf{5}$ & 2225 & 2100 & 30 & 2390 & 2500 \\
$\mathbf{6}$ & 2125 & 2300 & 31 & 2300 & 2400 \\
$\mathbf{7}$ & 2350 & 2400 & 32 & 1980 & 2200 \\
$\mathbf{8}$ & 2000 & 1900 & 33 & 1700 & 1550 \\
$\mathbf{9}$ & 2450 & 2600 & 34 & 1550 & 1400 \\
$\mathbf{1 0}$ & 1900 & 2050 & 35 & 2320 & 2500 \\
$\mathbf{1 1}$ & 1880 & 2000 & 36 & 2300 & 2430 \\
$\mathbf{1 2}$ & 2300 & 1950 & 37 & 2250 & 2500 \\
$\mathbf{1 3}$ & 2340 & 2500 & 38 & 1880 & 2000 \\
$\mathbf{1 4}$ & 2340 & 2500 & 39 & 2180 & 2300 \\
$\mathbf{1 5}$ & 2450 & 2200 & 40 & 1900 & 1800 \\
$\mathbf{1 6}$ & 2000 & 1810 & 41 & 1870 & 1700 \\
$\mathbf{1 7}$ & 2000 & 1750 & 42 & 2300 & 2450 \\
$\mathbf{1 8}$ & 2150 & 2300 & 43 & 2150 & 2200 \\
$\mathbf{1 9}$ & 2050 & 2300 & 44 & 2200 & 2300 \\
$\mathbf{2 0}$ & 2400 & 2600 & 45 & 1910 & 2000 \\
$\mathbf{2 1}$ & 2300 & 2500 & 46 & 2000 & 1900 \\
$\mathbf{2 2}$ & 2150 & 2200 & 47 & 2100 & 2300 \\
$\mathbf{2 3}$ & 2050 & 2050 & 48 & 2200 & 1900 \\
$\mathbf{2 4}$ & 2070 & 2100 & 49 & 2100 & 2150 \\
$\mathbf{2 5}$ & 2200 & 2150 & 50 & 2342 & 2250 \\
\hline & & & & & \\
\hline
\end{tabular}


Table 3: Correlation between actual birth weight and estimated fetal weight in control group at gestational age 37 to 40 weeks

\begin{tabular}{cccccc}
\hline S.No. & Birth Weight & EFW & S.No. & Birth Weight & EFWc \\
\hline $\mathbf{1}$ & 2560 & 2800 & 26 & 2800 & 2980 \\
$\mathbf{2}$ & 2800 & 3000 & 27 & 3500 & 3240 \\
$\mathbf{3}$ & 3050 & 2900 & 28 & 3070 & 3300 \\
$\mathbf{4}$ & 3200 & 3000 & 29 & 3180 & 3400 \\
$\mathbf{5}$ & 3100 & 3250 & 30 & 3200 & 3000 \\
$\mathbf{6}$ & 3500 & 3400 & 31 & 3300 & 3150 \\
$\mathbf{7}$ & 2900 & 3100 & 32 & 3340 & 3500 \\
$\mathbf{8}$ & 2880 & 2700 & 33 & 2990 & 3100 \\
$\mathbf{9}$ & 3200 & 3000 & 34 & 2788 & 3000 \\
$\mathbf{1 0}$ & 3400 & 3560 & 35 & 2590 & 2800 \\
$\mathbf{1 1}$ & 3450 & 3100 & 36 & 3400 & 3250 \\
$\mathbf{1 2}$ & 3100 & 2900 & 37 & 2660 & 2800 \\
$\mathbf{1 3}$ & 2900 & 3200 & 38 & 3220 & 3000 \\
14 & 2880 & 2700 & 39 & 3400 & 3250 \\
$\mathbf{1 5}$ & 2600 & 2870 & 40 & 3356 & 3500 \\
16 & 3100 & 3320 & 41 & 3200 & 3450 \\
$\mathbf{1 7}$ & 3150 & 3300 & 42 & 2970 & 3000 \\
18 & 3428 & 3670 & 43 & 2880 & 2700 \\
19 & 3456 & 3300 & 44 & 3040 & 3100 \\
$\mathbf{2 0}$ & 2890 & 3200 & 45 & 3450 & 3550 \\
$\mathbf{2 1}$ & 3450 & 3100 & 46 & 3200 & 2990 \\
$\mathbf{2 2}$ & 3440 & 3550 & 47 & 3260 & 3000 \\
$\mathbf{2 3}$ & 3200 & 3440 & 48 & 3468 & 3200 \\
$\mathbf{2 4}$ & 2890 & 3100 & 49 & 3148 & 3200 \\
$\mathbf{2 5}$ & 2730 & 2600 & 50 & 3100 & 3000 \\
\hline & & & & &
\end{tabular}

Table- 4: Comparison between AGA \& SGA

\begin{tabular}{lcccc}
\hline & Cases & $\begin{array}{c}\text { Overestimated fetal } \\
\text { weight }\end{array}$ & $\begin{array}{c}\text { Underestimated fetal } \\
\text { weight }\end{array}$ & \% Mean absolute error \\
\hline AGA & 50 & 28 & 22 & 0.48534 \\
SGA & 50 & 32 & 18 & 1.69953 \\
Total & 100 & 60 & 40 & 1.092435 \\
\hline
\end{tabular}

In our observation estimated fetal weight is over estimated in $56 \%$ and under estimated $44 \%$ in AGA fetuses. In case of SGA over estimation was $64 \%$ and under estimation was $46 \%$.

In our study the newborn birth weight range was $1500 \mathrm{gm}$ to 3500 gm. 50 cases with gestational age more than 37 completed weeks clinically classified as small for gestational age pregnancy were followed by ultrasound examination for determination of estimated fetal weight. Similarly 50 cases beyond 37 completed weeks clinically classified as appropriate for gestational age pregnancy were followed by ultrasound for estimation of fetal weight.

Similar study by Blumfeld $\mathrm{YJ}$ et $\mathrm{al}^{13}$ showed that ultrasound measurement of EFW in SGA pregnancies is consistent across all gestational age and EFW measurements. In their study there was no statistically significant difference in the mean absolute percent error across all gestational age ( $<32$ weeks, $32-36$ weeks, $>36$ weeks), and EFWs (<1500 g, 1500- $2000 \mathrm{~g},>2000 \mathrm{~g}$ ).

Larsen et al14 reported routine ultrasound screening for fetal weight estimation at three weeks interval starting from 28 weeks of gestation improved the diagnosis of small for gestational age fetuses, but this was not associated with improved fetal outcome. Atalie Colman et al ${ }^{15}$ collected data retrospectively for pregnant women who had undergone ultrasound estimation of fetal weight 7 days prior to a term delivery ( $\geq 37$ weeks) over the period of July 1998-June 2005. The mean absolute and mean signed error $( \pm S D)$ of ultrasound fetal weight estimations were 7.0 \pm 5.7 and $0.2 \pm 9.0$ respectively $(n=1777)$. The accuracy of ultrasound estimations of fetal weight performed was at least similar and sometimes better than reported in other studies. For one in four women, however the fetal weight estimation was more than $10 \%$ different from the actual birth weight if their infant were small for gestational age. Our study confirmed the finding of the studies of Larsen et al ${ }^{14}$ and Atalie Colmam et al. ${ }^{15}$ We found that there is no significant difference between adjusted ultrasound estimated fetal weight calculated using Hadlocks formula and actual birth weight of the neonate in both appropriate and small for gestational age pregnancies $(p>0.05)$. 
The mean absolute percent error for the entire sample was 1.092435 Mean absolute error for appropriate and small for gestational age pregnancies was 0.48534 and 1.69953 respectively. There is no statistically significant difference in the mean absolute percent errors between the two groups $(p>0.05)$. Percentage of overestimation of fetal weight is more in small for gestational age pregnancy as compared to appropriate for gestational age pregnancy (64\% versus $56 \%$ respectively). But the difference is not significant $(p>0.05)$.

\section{CONCLUSION}

The study showed that ultrasound predicts the fetal weight in both categories with a mean absolute error of 1.092435 USG estimation of fetal weight can be used to predict the birth weight with high degree of accuracy and plan delivery and neonatal management for a better neonatal outcome.

In clinically suspected small for gestational age pregnancies ultrasound estimation of fetal weight by Hadlocks formula is a valid estimate of actual birth weight and the preferred mode of diagnosis.

Accuracy of ultrasound estimation of fetal weight in small for gestational age pregnancies is comparable to accuracy of estimation of fetal weight in appropriate for gestational age pregnancies.

\section{REFERENCES}

1. Harlev A, Walfisch A, Bar- David J, Hershkovitz R, Friger M, Hallak $M$. Maternal estimation of fetal weight as a complementary method of fetal weight assessment: a prospective clinical trial. J Reprod Med. 2006 Jul; 51(7):515-20.

2. Williams RL, Creasy RK et al. Fetal growth and perinatal viability in California. Obstet Gynecol. 1982 May;59 (5):624-32.

3. DC Dutta's Textbook of Obstetrics 8th ed. 2015; pg84.

4. The investigation and management of the small- for- gestationalage fetus, RCOG. Guideline No. 31,2002, page no. 1-34.

5. Ott WJ. The diagnosis of altered fetal growth. Obstet Gynecol Clin North Am 1988; 15:237- 63.

6. Mclntire DD, Bloom SL, Casey BM, Leveno KJ. Birth weight in relation to morbidity and mortality among newborn infants. $\mathrm{N}$ Engl $\mathrm{J}$ Med 1999;340;1234- 8.
7. Roth s, Chang TC, Robson S, Spencer JA, Wyatt JS, Stewart AL. the neurodevelopmental outcome of term infants with different intrauterine growth characteristics. Early Hum Dev 1999;55:39- 50.

8. Barker DJ. The long- term outcome of retarded fetal growth. Clinobstet Gynecology 1997;40:853- 63.

9. Calvert JP, Crean EE, Newcombe RG, Pearson JF. Antenatal screening measurements bysymphysisfundal height. BMJ [Clin Res]. 1982;285:846- 9 .

10. McCormickk MC. The contribution of low birth weight to infant mortality and childhood morbidity. N Engl J Med. 1985;312:82- 90.

11. Director General World Health Organization. Bridging the gaps. The World Health Report 1995.

12. Queenan JT, ed. Management of high- risk pregnancy. 3rded. Boston: Blackwell Scientific, 1994:402- 12.

13. Blumenfeld YJ, Lee HC, Pullen LM, Wong AE, Pettitk, Taslimi MM. Ultrasound estimation of fetal weight in small for gestational age pregnancies. American Journal of Matern Fetal Neonatal Med. 2010 Aug; 23(8):790- 3.

14. Larsen $T$, Larsen JF, Petersen S, Greisen G, Detection of smallfor- gestational- age fetuses by ultrasound screening in a high risk population : a randomized controlled study. $\mathrm{Br} \mathrm{J}$ ObstetGynaecol. 1992 Jun; 99(6):469- 74.

15. Atalie Colman, Dushyant Maharaj, John Hutton, Jeremy Tuohy. Reliability of ultrasound estimation of fetal weight in term singleton pregnancies. Journal of the New Zealand association, 08September- 2006, Vol 119 No. 1241.

\section{Source of Support: Nil. Conflict of Interest: None Declared.}

Copyright: (c) the author(s) and publisher. IJMRP is an official publication of Ibn Sina Academy of Medieval Medicine \& Sciences, registered in 2001 under Indian Trusts Act, 1882.

This is an open access article distributed under the terms of the Creative Commons Attribution Non-commercial License, which permits unrestricted non-commercial use, distribution, and reproduction in any medium, provided the original work is properly cited.

Cite this article as: Manoj Kumar Malhotra, Deepali Jain. Accuracy of Ultrasound Determination of Estimated Fetal Weight in Small for Gestational Age Pregnancies. Int J Med Res Prof. 2016; 2(4):57-61. 